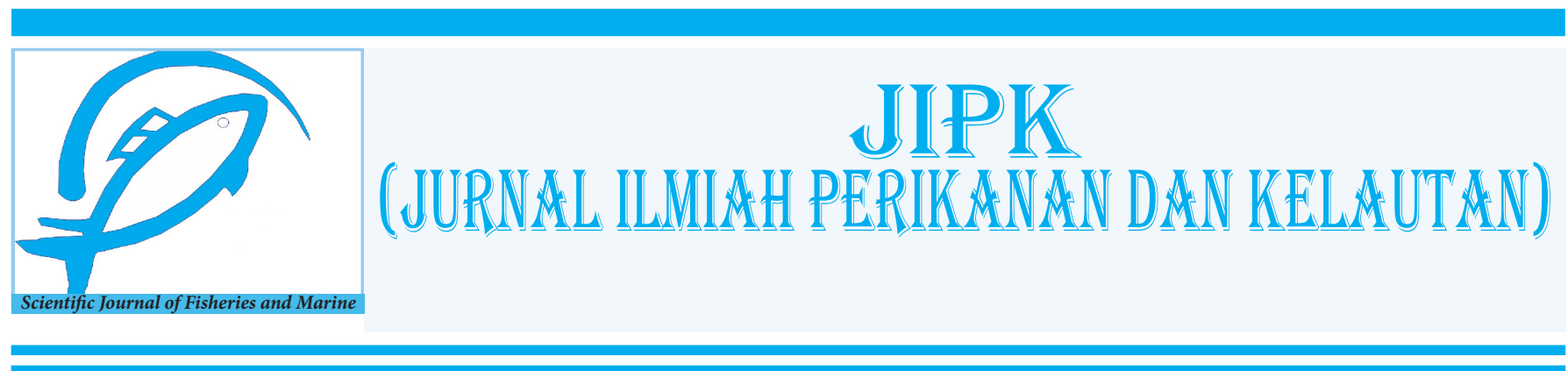

Research Article

\title{
Effect of Homogenization Process on the Production of Arthrospira platensis Carotenoid Nanocapsules Encapsulated with Arabic Gum and Whey Protein Concentrate
}

\author{
Khusnul Alfionita, Siti Ari Budhiyanti*, (D), and Nurfitri Ekantari \\ Department of Fisheries, Faculty of Agriculture, Universitas Gadjah Mada. Indonesia
}

\section{OPEN \\ ACCESS}

\section{ARTICLE INFO}

Received: December 07, 2021

Accepted: February 24, 2022

Published: February 25, 2022

*) Corresponding author:

E-mail: sitabudhiyanti@ugm.ac.id

Keywords:

Arthrospira platensis

Homogenization Process

High Shear Homogenizers

Ultrasound

Nanocapsules

This is an open access article under the CC BY-NC-SA license (https://creativecommons.org/ licenses/by-nc-sa/4.0/)

\section{Abstract}

Arthrospira platensis contains a high concentration of carotenoids mainly $80 \% \beta$-carotene. The use of $\beta$-carotene in functional food and nutritional supplements was constrained by its lack of chemical and physical stability. Therefore, efforts were needed to protect carotenoids from damage by using an encapsulation system. The emulsion preparation before the encapsulation process had an influence on the stability of the oil-inwater emulsion. Various methods were used to prepare emulsions, such as high shear homogenizers (HSH) and ultrasound (US) treatment. The homogenization step was critical because it influenced the chemical stability of any encapsulated compounds. The purpose of this work was to generate nanocapsules of $\beta$-carotene with minimum carotenoid degradation, high efficiency of encapsulation, and small particle size, with variation in the homogenization process. This study consisted of 5 treatments, including the homogenization processes used HSH $24.000 \mathrm{rpm}$ for $90 \mathrm{~s} ; \mathrm{HSH}$ $24.000 \mathrm{rpm}$ for $60 \mathrm{~s}$, amplitude $55 \%$ for $120 \mathrm{~s}$; amplitude $94 \%$ for $138 \mathrm{~s}$; amplitude $55 \%$ for $138 \mathrm{~s}$; and amplitude $55 \%$ for $120 \mathrm{~s}$. Each parameter was analysed by ANOVA followed by Tukey pairwise comparisons with $95 \%$ confidence level and $p<0.05$. The particle size was influenced by the emulsification process, such as homogenization treatment, homogenization time, amplitude, and time of sonication. The sample that was homogenized using both HSH and US had a smaller particle size and the highest efficiency in encapsulation than others. The combination of homogenization process could decrease particle size.

Cite this as: Alfionita, K., Budhiyanti. S. A., \& Ekantari, N. (2022). Effect of Homogenization Process on the Production of Arthrospira platensis Carotenoid Nanocapsules Encapsulated with Arabic Gum and Whey Protein Concentrate. Jurnal Ilmiah Perikanan dan Kelautan, 14(1):12-24. http://doi.org/10.20473/jipk.v14i1.30074 


\section{Introduction}

Arthrospira is a photosynthetic, filamentous, spiral-shaped, multicellular blue-green microalgae and an essential microalga with a high content of valuable pigment. Arthrospira platensis has a high protein content, carotenoids (mainly $\beta$-carotene), essential fatty acids, vitamins, and minerals (Belay, 2007; Mani et al., 2008). Carotenoids are responsible for the red and yellow hues in nature, with an average of 3.4 to 4.0 $\mathrm{g} / \mathrm{kg}$ in A. platensis. $\beta$-carotene content is $80 \%$ of the carotenoids content in Arthrospira, which is converted into vitamin A (Sotiroudis and Sotiroudis, 2013). Rather than its provitamin $\mathrm{A}$ function, $\beta$-carotene can perform as an antioxidant (Kasperczyk et al., 2014), decreasing the risk of type 2 diabetes, promoting immune system function, and lowering the risk of cardiovascular disease (Tanaka et al., 2012). Nevertheless, $\beta$-carotene's use in functional foods and nutritional supplements is constrained by its lack of physical and chemical stability (Chen and Zhong, 2015).

Carotenoids are easily oxidized and damaged due to heat, which affects their stability in the product. Due to the presence of highly conjugated double bonds in its structure, a bioactive chemical such as carotenoid is easily oxidized and susceptible to light, heat, and singlet oxygen during food processing and storage, resulting in the loss of both its color and bioactivity. Therefore, efforts are needed to protect carotenoids from damage due to heat, oxidation, light, or isomerization by using an encapsulation system (Ferreira and Nunes, 2019). Encapsulation is the process of encasing bioactive compounds in a heterogeneous or homogeneous matrix to form small capsules with microscales $(>1000 \mathrm{~nm}$ ) or nanoscales $(<1000 \mathrm{~nm})$ (Rodríguez et al., 2016; Ricaurte et al., 2016; Sanguansri and Augustin, 2006). Encapsulation is a potential approach in which a bioactive compound is protected by a wall material that preserves the natural bioactive properties over time. The form of bioactive encapsulation will maintain, release, stabilize, and control the release of the bioactive compound. Incorporating $\beta$-carotene into the emulsion before the spray drying process can improve its functional properties. $\beta$-carotene bioaccessibility may be enhanced by the incorporation of oil-in-water emulsions due to the higher solubility of $\beta$-carotene in food-grade oils than in water (Qian et al., 2012; Salvia et al., 2013a; Salvia et al., 2013b). It can be dissolved in the oils and subsequently diffused in an aqueous phase in the form of smaller lipid droplets utilizing homogenization techniques (McClements and Rao, 2011).

Emulsions are thermodynamically unstable systems in which oil and water rapidly separate from one another. The emulsifier stabilized the system by producing a thin layer surrounding the dispersed phase globules (Ghosh and Rousseau, 2011). Different densities between oil and the aqueous phase, combined with the unfavorable interaction of oil and water molecules, result in the formation of distinct layers (Kerkhofs et al., 2011; Maphosa et al., 2017). Thus, the production of emulsion-based materials requires an understanding of the rheology, stability, and bioavailability of active chemicals in order to produce products with the desired physical properties. The method had an effect on the oil-in-water emulsion's stability. Alcântara et al. (2019) reported that the efficiency of chia oil encapsulation was higher with the combination of the homogenization process (ultraturrax and ultrasound). A combination of homogenization and sonication time for solid lipid nanoparticle was also reported by Behbahani et al. (2017), that emulsion's particle size was affected by homogenization time. Other research about amplitude and sonication time was reported by Gaikwad and Pandit (2008), Higuera-Barraza et al. (2017), and Hussathirak et al. (2019). At the moment, emulsions are prepared using a variety of processes, including high shear homogenizers and ultrasonic (US) treatment. The shear force was generated by the cavitation of US power, which dispersed oil droplets into microscopic particles with a limited size distribution. Additionally, numerous investigations indicated that US power could produce stable oil-in-water emulsions. Kumalasari and Budhiyanti (2015) and Alfionita et al. (2017) suggested that a high shear homogenizer (HSH) might be used to minimize the size and homogeneity of droplets in order to maintain emulsion stability.

The important aspect of emulsion for commercial or industrial applications was to transform a nutraceutical delivery system's liquid into a powder to permit easy handling and utilization while also extending shelf life (Maher et al., 2014). Spray drying is a low-cost encapsulation technology widely used in the food and pharmaceutical industries because it is suitable for continuous large-scale powder production, relatively simple, inexpensive, fast, and reproducible. This short operational duration may lessen the risk of heat-sensitive components being damaged (Dias et al., 2015). Previous studies suggested that optimizing emulsification process conditions and product formulation was required for successful formulation of a powdered delivery system (core material and wall material) (Mao et al., 2010; McClements and Rao, 2011; Behbahani et al., 2017). The incorporation of wall material into an emulsion prior to dehydration was significant because it raised the glass transition temperature of the solid matrix around the oil droplets, boosting the chemical stability of any 
encapsulated compounds (Mosquera et al., 2012).

Arabic gum and whey protein concentrate were used for wall material due to their high encapsulation efficiency and good volatile retention (Carneiro et al., 2013; Kumalasari and Budhiyanti, 2015; Hidayat et al., 2016; Vahidmoghadam et al., 2019). Arabic gum has been utilized as a wall material in various encapsulation processes, for example, in the microencapsulation and nanoencapsulation of oils, volatile bioactive chemicals, and flavorings, among other applications (Krishnan et al., 2005; Soottitantawat et al., 2005; Fang et al., 2005; Vaidya et al., 2006) and Prata et al. (2013) also found that whey protein concentrates had the greatest emulsifying potential. $\beta$-carotene nanoencapsulation with arabic gum and whey protein concentrate is expected to maintain the quality of carotenoids, allowing for greater use of $\beta$-carotene nutrients. The objective of the current study was to develop nanocapsules of $\beta$-carotene with minimum carotenoid degradation, high efficiency of encapsulation, and small particle size, with variation in the homogenization process.

\section{Materials and Methods}

\subsection{Material}

The materials in this research are $A$. platensis (purchased from PT. Trans Pangan Spirulindo, Indonesia), n-hexane (Merck, Germany), ethanol (Merck, Germany), virgin coconut oil or VCO (CV. Pusat Pengolahan Kelapa Terpadu, Indonesia), Arabic gum (Medika, Indonesia), whey protein concentrate or WPC (Carnivor, Indonesia), and distilled water.

\subsection{Sample Preparation}

Arthrospira platensis was extracted according to Wahyu and Yanuar (2010) and Pahlevi et al. (2008). The extraction process was started by weighing 9 grams of $A$. platensis, then placed in the three-neck flask layered aluminium foil, attached to the spiral condenser and hot plate stirrer, then added with $27 \mathrm{~mL}$ ethanol and $270 \mathrm{~mL}$ hexane solvent. The extraction process took 3 hours and 24 minutes, with a hot plate stirrer set at 1500 $\mathrm{rpm}$ and $51.9^{\circ} \mathrm{C}$. After that, the carotenoid extract was separated from the pellet and evaporated using a rotary vacuum evaporator for 20 minutes at $45^{\circ} \mathrm{C}$. The extract was sprayed with nitrogen to evaporate all solvent and to produce the condensed carotenoid extract. The carotenoid extract was kept at $0 \pm 2^{\circ} \mathrm{C}$ in a glass-wrapped by aluminium foil until it used.

\subsection{Emulsion Production}

First, $0.36 \mathrm{~g}$ carotenoid extract was diluted in $10 \mathrm{~mL}$ VCO in a volumetric flask and sealed with aluminum foil to protect it from light. After that, $18 \mathrm{~g}$ of Arabic gum and $9 \mathrm{~g}$ of WPC was diluted into $90 \mathrm{~mL}$ distillate water as a mix of encapsulating material. The mix was stirred at $60^{\circ} \mathrm{C}$ and $600 \mathrm{rpm}$ for 30 minutes, then decreased in temperature to $45^{\circ} \mathrm{C}$ (Rosanita, 2014; Kumalasari and Budhiyanti, 2015). Finally, the carotenoid dilution and encapsulating material were mixed with various methods using a high-speed homogenizer and or ultrasound (Table 1).

\subsection{Spray Drying}

The spray drying process was used to convert the carotenoid emulsion into encapsulated powder. The carotenoid emulsion was pumped into a spray dryer chamber. The drying process was controlled to keep $150^{\circ} \mathrm{C}$ for inlet temperature and $70^{\circ} \mathrm{C}$ for outlet temperature using Büchi Mini Spray Dryer B-290 (made from Switzerland). The encapsulated powder was collected and placed in a dark glass bottle, and kept frozen before use for further analyzed.

\subsection{Nanocapsules Characteristics Analysis}

\subsubsection{Emulsion stability analysis}

Emulsion stability was analyzed using creaming index after the homogenization process (Cho et al., 2008). The emulsion was placed at a conical bottle then were centrifuged at $2300 \mathrm{rpm}$ for 15 minutes. The emulsion stability was expressed as the percentage of the emulsified layer volume remaining in the original emulsion volume.

\subsubsection{Carotenoid content analysis}

\subsubsection{Total carotenoid}

Carotenoid content analysis used the Desorby et al. (1997) method with modification. Total carotenoid, surface carotenoid, and retention of carotenoid were evaluated respectively after the spray drying process. Total carotenoid was measured by placing $50 \mathrm{mg}$ of capsule powder into an Erlenmeyer flask, then adding $0.25 \mathrm{~mL}$ of dilute water and $2.5 \mathrm{~mL}$ of $\mathrm{n}$-hexane for analysis. It was stirred at $500 \mathrm{rpm}$ for 30 minutes. The supernatant was read by a spectrophotometer (Genesys 10 UV-VIS) at a wavelength of $450 \mathrm{~nm}$. The absorbance was converted to the standard curve of the carotenoid. Total carotenoid was calculated by using the following equation:

Total carotenoid $(\mu \mathrm{g} / \mathrm{mg} \mathrm{db})=\frac{\text { Total carotenoid }}{100-\mathrm{Ka}} \times 100$ 
Table 1. Various homogenization processes of Arthrospira platensis carotenoid emulsion

\begin{tabular}{|c|c|c|c|c|}
\hline \multirow{3}{*}{$\begin{array}{c}\text { Sample } \\
\text { code* }\end{array}$} & \multicolumn{3}{|c|}{ Homogenization process } & \multirow{3}{*}{ References } \\
\hline & \multirow{2}{*}{$\begin{array}{l}\text { High speed homogenizer } \\
\text { (HSH) } 24,000 \mathrm{rpm} \\
\text { Time (s) }\end{array}$} & \multicolumn{2}{|c|}{ Ultrasound } & \\
\hline & & Amplitude (\%) & Time (s) & \\
\hline $\mathrm{A}$ & 90 & --- & --- & Kumalasari and Budhiyanti (2015) \\
\hline $\mathrm{B}$ & 60 & 55 & 120 & Hidayat et al. (2016) \\
\hline $\mathrm{C}$ & --- & 94 & 138 & Hashtjin and Abbasi (2015) \\
\hline $\mathrm{D}$ & --- & 55 & 138 & Optimization \\
\hline $\mathrm{E}$ & --- & 55 & 120 & Optimization \\
\hline
\end{tabular}

*Each sample code was replicated two times.

Table 2. Carotenoid contents of A. platenis carotenoid encapsulated with Arabic Gum and Whey Protein Concentrate

\begin{tabular}{ccccc}
\hline Treatment & Surface carotenoid & Total carotenoid & Encapsulation retention & Efficiency encapsulation \\
\hline A & $28.20 \pm 1.17^{\mathrm{d}}$ & $73.04 \pm 0.35^{\mathrm{b}}$ & $72.35 \pm 0.35^{\mathrm{b}}$ & $61.39 \pm 1.41^{\mathrm{b}}$ \\
\hline $\mathrm{B}$ & $17.56 \pm 0.13^{\mathrm{e}}$ & $66.53 \pm 1.93^{\mathrm{c}}$ & $65.89 \pm 1.91^{\mathrm{c}}$ & $73.58 \pm 0.96^{\mathrm{a}}$ \\
\hline $\mathrm{C}$ & $72.81 \pm 0.49^{\mathrm{a}}$ & $122.3 \pm 1.76^{\mathrm{a}}$ & $121.13 \pm 1.74^{\mathrm{a}}$ & $40.46 \pm 0.46^{\mathrm{d}}$ \\
\hline $\mathrm{D}$ & $59.30 \pm 0.7^{\mathrm{b}}$ & $66.83 \pm 0.36^{\mathrm{c}}$ & $66.19 \pm 0.35^{\mathrm{c}}$ & $11.26 \pm 0.57^{\mathrm{e}}$ \\
\hline $\mathrm{E}$ & $38.49 \pm 0.69^{\mathrm{c}}$ & $75.32 \pm 25.45^{\mathrm{b}}$ & $74.60 \pm 0.48^{\mathrm{b}}$ & $48.9 \pm 0.59^{\mathrm{c}}$ \\
\hline
\end{tabular}

Description: Different superscripts in the same column shows that there are significant differences $(\mathrm{p}<0.05)$ : A : High Speed Homogenizer (HSH) 24,000 rpm, $90 \mathrm{~s}$; B : HSH 24,000 rpm, $60 \mathrm{~s}$, Ultrasound (US) Amplitude $55 \%$, $120 \mathrm{~s}$; C : US Amplitude $94 \%, 138$ s; D : US Amplitude $55 \%, 138$ s; E US Amplitude $55 \%, 120$ s

\subsubsection{Surface Carotenoid}

The carotenoid surface was calculated by placing $50 \mathrm{mg}$ of powder into an Erlenmeyer flask, adding $0.25 \mathrm{~mL}$ of dilute water and $2.5 \mathrm{~mL}$ of $\mathrm{n}$-hexane for analysis, then stirring at $100 \mathrm{rpm}$ for 15 seconds. The sample was centrifuged at $1000 \mathrm{rpm}$ for 1 minute. The supernatant was analyzed by a spectrophotometer at a $450 \mathrm{~nm}$ wavelength. Carotenoid surface was calculated by the following equation:

Surface carotenoid $(\mu \mathrm{g} / \mathrm{mg} \mathrm{db})=\frac{\text { Surface carotenoid }}{100-\mathrm{Ka}} \times 100$

\subsubsection{Carotenoid retention}

The carotenoid retention ratio was a ratio between the carotenoid levels in the nanocapsules after spray drying with the initial carotenoid extract levels before the nanoencapsulation process (Desorby et al., 1997). Carotenoid retention was calculated by using the following equation:

$\%$ carotenoid retention $=\frac{\text { Total carotenoid }}{\text { Initial carotenoid extract }} \times 100$

\subsubsection{Encapsulation efficiency (EE)}

The encapsulation efficiency was carried out to measure the effectiveness of the nanoencapsulation process in trapping the core material (Alcântara et al., 2019). Encapsulation efficiency was expressed by using the following equation:

$\% \mathrm{EE}=\frac{\text { Total carotenoid }- \text { Surface carotenoid }}{\text { Total carotenoid }} \times 100$

\subsubsection{Particle size distribution and droplet size}

Particle size distribution and droplet size was analyzed from encapsulated powder. Particle size analysis was carried out using a particle size analyzer or PSA (Horiba scientific SZ-100 type made from Japan) according to Liang et al. (2013). Five milliliters sample was placed into a cuvette by pipette then the cuvette was put into PSA tool. The result of particle size and polydispersity index was displayed on the computer. 


\subsubsection{Antioxidant activity}

Antioxidant activity was analysed using the scavenging effect of antioxidants on 2,2-diphenyl-1picrylhydrazyl (DPPH). The encapsulated powders were diluted in methanol at a $1 \mathrm{mg} / \mathrm{ml}$ concentration. $1 \mathrm{~mL}$ of DPPH dilution was mixed with $1 \mathrm{~mL}$ of encapsulated powder (O'Sullivan, 2013). After incubating the sample in a dark room for 15 minutes, the absorbance was measured using a spectrophotometer with a $515 \mathrm{~nm}$ wavelength. DPPH solution and methanol were used as a control with the same amount of sample. The absorbance value was used to calculate radical scavenging activity ( $\%$ of inhibition) with the formula:

$\%$ inhibition $=\frac{(\text { Abs control }- \text { Abs encapsulated powders })}{\text { Abs control }} \times 100 \%$

\subsubsection{Statistical analysis}

Each parameter was analysed by one-way ANOVA followed by Tukey pairwise comparisons post hoc using Tukey's method with $95 \%$ confidence level and $p<0.05$. Statistical analysis was performed using Minitab 19 software.

\section{Result and Discussion}

\subsection{Emulsion Stability}

The emulsion-making process used by $\mathrm{HSH}$ and US in various conditions was shown in Table 1, and the emulsion stability of the carotenoid emulsion was shown in Figure 1. The sample code E (55\% amplitude level and 120 seconds) had the highest stability (72\%) compared to the others. However, it was not significantly different from sample C (94\% amplitude level for 138 seconds) (65\%). On the other hand, sample $\mathrm{C}$ was not significantly different from sample A (high speed homogenizer for 90 seconds) (57\%), B (high-speed homogenizer for 60 seconds and ultrasound at 55\% amplitude level for 120 seconds) (58\%), and D (55\% amplitude level for 138 seconds) (59\%). The result showed that HSH had no effect on the formation of a stable emulsion. The cavitation of US power generated the shear force, which could disperse oil droplets into small particles with a narrow size distribution. Also, many studies mentioned that US power could produce oil-in-water emulsions with good stability (Chemat et al., 2011; Bajac et al., 2019). The instability of the emulsion system was shown by the creaming in the system. Based on the results, sample E (55\% amplitude level and 120 seconds) had the highest stability emulsion, which was processed by US. It may be because sonication could be able to form a stable emulsion through cavitation,

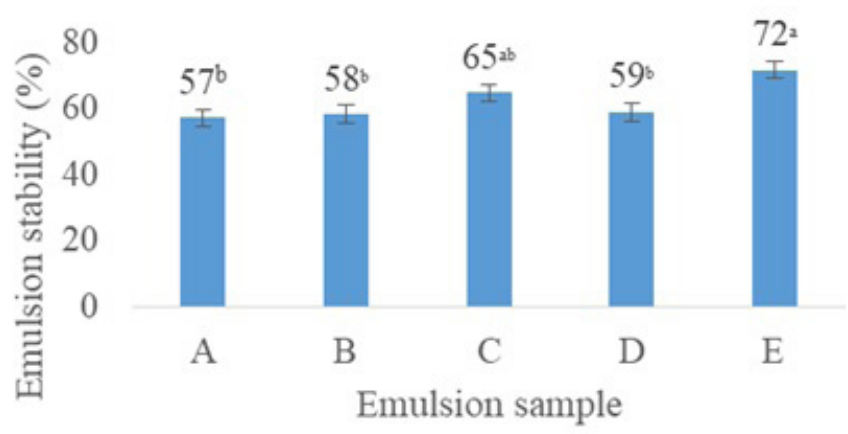

Figure 1. The emulsion stability of carotenoid A. platensis emulsion. Description: Different superscripts shows that there are significant differences $(p<0.05)$ : A : High Speed Homogenizer (HSH) 24,000 rpm, $90 \mathrm{~s}$; B : HSH 24,000 rpm, $60 \mathrm{~s}$, Ultrasound (US) Amplitude 55 $\%, 120 \mathrm{~s} ; \mathrm{C}$ : US Amplitude $94 \%, 138 \mathrm{~s}$; D : US Amplitude $55 \%$, $138 \mathrm{~s}$; E US Amplitude $55 \%, 120 \mathrm{~s}$

but based on the particle size powder obtained from the spray drying process, sample $\mathrm{E}$ had the highest surface oil. Emulsion stability was one of the parameters for knowing the emulsion resistance during the waiting period before spray drying.

The stability of carotenoid emulsions could be determined by monitoring the layer's height over time. Typically, the droplets in an emulsion had a different density than the liquid that surrounds them (McClements, 2005). Because the emulsifier had a higher density than the oil in this study, the oil droplets tended to rise upward, a phenomenon referred known as "creaming" (Tadros, 2013). Due to the fact that the densities of the majority of edible oils were lower than those of water, oil tended to accumulate at the top of an emulsion and water at the bottom. By centrifuging an emulsion at a constant speed for a specified period of time, the creaming instability of the emulsion could be enhanced (Sherman, 1995). The emulsion preparation method had a great influence on the stability of oil in water emulsion. Different emulsion preparation procedures tend to produce emulsions with varying degrees of stability. Numerous breakdowns of emulsions were possible, including creaming or sedimentation, which occurred when two or more droplets mix to produce a droplet with a larger volume but a smaller area, and flocculation caused by Van der Walls attraction, which occurred when the droplets lack adequate repulsion (McClements, 2005). Additionally, the breakdown could be triggered by Ostwald ripening, which was caused by differences in the chemical potentials of the materials within the small and large droplets; coalescence, which was triggered by the thinning and disruption of the liquid film between 
Alfionita et al. / JIPK, 14(1):12-24

Table 3. Particle size of $A$. platenis carotenoid encapsulated with with Arabic Gum and Whey Protein Concentrate

Treatment Capsule particle size (nm)

Polydispersity Index

(PDI)

$\begin{array}{lll}\text { A } & 839.9667 \pm 11.38^{\mathrm{a}} & 0.519^{\mathrm{a}} \\ \text { B } & 743.1667 \pm 6.08^{\mathrm{a}} & 0.503^{\mathrm{a}} \\ \text { C } & 1420.467 \pm 0.92^{\mathrm{c}} & 0.455^{\mathrm{a}} \\ \text { D } & 1321.533 \pm 40.8^{\mathrm{bc}} & 0.538^{\mathrm{a}} \\ \text { E } & 1260.767 \pm 14.14^{\mathrm{b}} & 0.508^{\mathrm{a}}\end{array}$

Description: Different superscripts in the same column shows that there are significant differences $(\mathrm{p}<0.05)$. A : High Speed Homogenizer (HSH) 24,000 rpm, $90 \mathrm{~s}$; B : HSH 24,000 rpm, $60 \mathrm{~s}$, Ultrasound (US) Amplitude $55 \%$, $120 \mathrm{~s}$; C : US Amplitude 94 \%, 138 s; D : US Amplitude 55 \%, 138 s; E US Amplitude 55 \%, $120 \mathrm{~s}$

the droplets; or phase inversion, which occurs when the dispersion phase and medium exchange positions (Tadros, 2004).

Meybodi et al. (2014) mentioned that the presence of oil oxidation could increase instability of the emulsion due to droplet aggregation. In the emulsion phase, physical characteristics such as stability were key issues that should be considered. Emulsion stability referred to the ability of the emulsion to withstand changes in its characteristics over a certain period of time. The level of emulsion size was determined by several factors, including particles, particle size distribution, and density between the dispersed phase and the continuous phase (Given, 2009). In addition, emulsion stability was needed to predict the presence of droplet aggregation over a certain period of time.

\subsection{Carotenoid Content}

Carotenoid contents were the chemical parameter of $A$. platensis carotenoid nanocapsules, including surface carotenoid, total carotenoid, carotenoid retention, and encapsulation efficiency. The difference in carotenoid contents is due to different homogenization processes (Table 2). The $\mathrm{C}$ sample (94\% amplitude level for 138 seconds) had the highest total carotenoid and carotenoid retention but had low encapsulation efficiency. The encapsulation efficiency in sample B (high-speed homogenizer for 60 seconds and ultrasound at 55\% amplitude for 120 seconds) was higher than others, indicating that the emulsion process fit the carotenoid emulsion. The other fact was that the surface carotenoid in the B (high speed homogenizer for 60 seconds and ultrasound at 55\% amplitude for 120 seconds) sample was lower than in the others. It indicated that the homogenization process produced good emulsion stability, the wall material could entrap the core material, and prevent damage during the spray drying process. Reineccius (2004), Li et al. (2016), and Vahidmoghadam et al. (2019) stated that one of the important parameters to determine good encapsulation process was surface oil content and encapsulation efficiency because it was related to the quality of the resulting capsule structure.

The homogenization processes of $\mathrm{B}$ and $\mathrm{C}$ were different. B used a $24.000 \mathrm{rpm}$ high-speed homogenizer (HSH) for 60 seconds and ultrasound with a 55\% amplitude for 120 seconds, but $\mathrm{C}$ used ultrasound with a 94\% amplitude for 138 seconds without a high-speed homogenizer. Hashtjin and Abbasi (2015) explained that nanoemulsion of peeled orange essential oil was used with ultrasound at 94\% amplitude and for 138 seconds as the optimum homogenization condition to produce an emulsion with Tween 80 emulsifier, but in this research, the emulsion method was not appropriate for applying carotenoid extract emulsion with arabic gum and whey protein concentrate based on carotenoid contents and particle size.

The $\mathrm{D}$ sample that was homogenized by ultrasound with 55\% amplitude for 138 seconds showed the high content of surface carotenoid (59.30 $\mu \mathrm{g} / \mathrm{mg} \mathrm{db}$ ) and the lowest efficiency of encapsulation (11.26\%). Compared to the A sample, there was a significant difference between surface carotenoid and encapsulation efficiency, which had $28.20 \mathrm{~g} / \mathrm{mg} \mathrm{db}$ and $61.39 \%$, respectively. This data revealed that the high-speed homogenizer played an essential role in the homogenization process of the carotenoid emulsion. McClements (2004) stated that stirring at a certain speed and time in the emulsion system could increase the absorption of the emulsifier so that the emulsifier could cover the oil components and reduce the droplet 
interfacial tension. The oil component, which was well adsorbed by the emulsifier, caused the oil content on the capsule surface to be lower and the encapsulation efficiency to be higher. In addition, energy input during the emulsification process also played an important role in the stability of the emulsion formed. Stable emulsion could produce stable capsule powder after passing through the spray drying process (Mohammed et al., 2020). The B sample (high-speed homogenizer for 60 seconds and ultrasound at 55\% amplitude for 120 seconds) got more energy input because there were two processing times during emulsion formation. Based on this, it could be concluded that B sample emulsion and powder were more stable than the other four samples. This was evidenced by the low carotenoid content and high encapsulation efficiency in sample B. Similar results were shown by the study of Alcântara et al. (2019) using a high speed homogenizer with ultrasonication as a homogenizer for microencapsulation of chia seed oil (Salvia hispanica L.). Alcântara et al. (2019) showed the results of the lowest surface oil content and the highest encapsulation efficiency when using a high speed homogenizer and ultrasonication during emulsion formation.

\subsection{Particle Size}

The A sample (high-speed homogenizer for 90 seconds) and B sample (high-speed homogenizer for 60 seconds and ultrasound at 55\% amplitude for 120 seconds) showed smaller particle size than C $(94 \%$ amplitude for 138 seconds), D (55\% amplitude level for 138 seconds), and E (55\% amplitude level for 120 seconds) samples. Based on statistical analysis (Table $3)$, the particle size of B had no significant difference with that of $\mathrm{A}$, where the homogenization process was done without ultrasound. The A used HSH only for 90 seconds and the B used HSH at 24,000 rpm for 60 seconds and ultrasound $55 \%$ amplitude for 120 seconds. On the other hand, the $\mathrm{C}$ sample was homogenized only by ultrasound at $94 \%$ amplitude for 138 seconds. The particle size of the $\mathrm{C}$ was twice that of the $\mathrm{B}$. This revealed that the HSH was an important step in producing small particles of carotenoid encapsulated by arabic gum and whey protein concentrate. Higher sonicator intensities, on the other hand, may result in faster droplet coalescence (Jafari et al., 2006; Li and Chiang, 2012). Longer sonication (more than 120 seconds) and higher amplitude (more than 55 percent) may result in larger droplets forming due to coalescence.

Nanoparticles were produced from bioactive compounds or native oil and recovered or enclosed by a homogeneous or heterogeneous matrix as a wall material to create small particles with a size of $10-1000$ nm (Mohanraj and Chen, 2006). The particle size and size distribution of the particles were the most critical aspects to consider in order to ensure stability, targeting ability, biological destiny, loading, and release of the bioactive during application. There is a possibility that it will determine the stability and bioavailability of nanoparticles. The Particle Size Analyzer (PSA) was utilized for particle size analysis, and the polydispersity index was used to describe the size distribution of the particles (PDI). It was discovered by Gaumet et al. (2008) that size (mean diameter or z-average) and size distribution were important parameters for nanoencapsulation evaluation because of their relationship to distribution, physicochemical changes of the encapsulated compounds, viscosity, and surface area of the nanoparticles, among other things.

The preparation method to obtain a good emulsion always involves homogenization. The control of homogenization conditions (speed, pressure, temperature, and cycles) is required to obtain emulsions with the desired properties (droplet size, stability, encapsulation, and biocompound delivery (Yuan et al., 2008). At greater homogenization speeds, a higher energy density was applied to the solution, which resulted in a reduction in the size of the emulsion droplet. Shear stress was also shown to be inversely proportional to the size of the emulsion droplets. Increasing shear stress results in a reduction in droplet size and the formation of nanodroplets. After migrating through the rotorstator area, the mean droplet size decreased relatively little, although it varied according to speed, time, and emulsion components (Hakansson and Rayner 2018). Ultrasound was a technique that can be employed in liquid systems. It was characterized as high-frequency waves followed by the breakup of droplets due to cavitation effects (Létang et al., 2001; Peshkovsky and Bystryak, 2014). Sound waves may cause particle size reduction, resulting in inhomogeneous particles ranging non size from micro to nano. To achieve tiny particles, both US and HSH were utilized in the homogenization process during emulsification. Tadros (2004) said that the stability, appearance, color, and texture of emulsion systems are dependent on the emulsion droplets and particle size distribution. According to Stokes' Law, droplet diameter was critical in determining oil-in-water emulsion stability because creaming and sedimentation occur due to the gravitational effect. There was a direct correlation between oil droplet diameter and emulsion stability. As mentioned before, $\mathrm{McClements} \mathrm{and} \mathrm{Decker}$ (2000) also stated that reducing droplet size will enhance the emulsion stability and is thermodynamically stable. 


\subsection{Yield}

The yield of capsule powders produced by spray drying (Figure 2). Differences in the homogenization process were not significantly different among the five treatments on A, B, C, and D samples. The data showed that the homogenization process did not significantly affect the yield, as Tontul and Topuz (2015) and Tontul and Topuz (2013) mentioned that yield was not affected by the homogenization during the emulsification process but the wall materials.

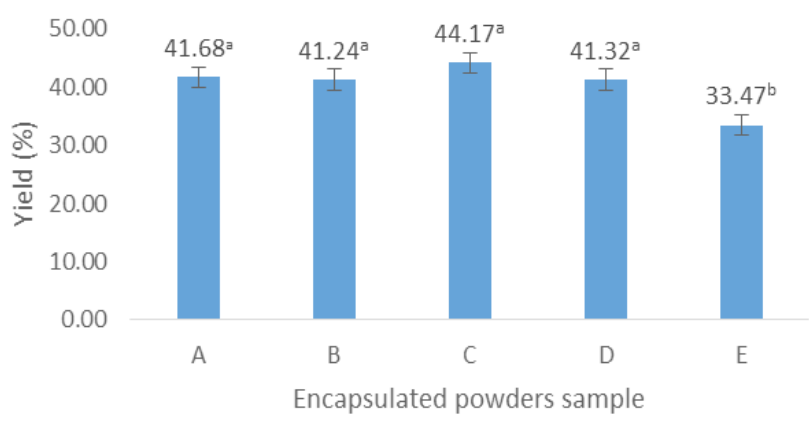

Figure 2. The yield of $A$. platenis carotenoid encapsulated with Arabic Gum and Whey Protein Concentrate. Description: Different superscripts in the same column shows that there are significant differences $(p<0.05)$ A : High Speed Homogenizer (HSH) 24,000 rpm, $90 \mathrm{~s}$; B : HSH 24,000 rpm, $60 \mathrm{~s}$, Ultrasound (US) Amplitude $55 \%, 120 \mathrm{~s}$; C : US Amplitude $94 \%, 138 \mathrm{~s}$; D : US Amplitude $55 \%, 138 \mathrm{~s}$; E US Amplitude $55 \%, 120 \mathrm{~s}$

\subsection{Moisture Content}

Moisture content is a critical quality control factor, affecting the appropriateness, storage behaviour, and stability of the powder. The moisture content of the powder ranged from 2.68 to 5.30 percent (Figure 3). Sample E had the lowest moisture content of the others. Samples A and B presented no significant difference by ANOVA analysis $(\mathrm{p}<0.05)$. Higher moisture content was affected by the manufacturing of the capsules. Due to insufficient powder flow during the spray drying process, capsule performance would be inconsistent. Additionally, it may result in capsule surface adhesion problems (Tomar et al., 2017). Crouter and Briens (2014) indicated that powder characteristics and behaviours were crucial for efficient and successful powder manufacture. The hygroscopicity of a powder might indicate its capacity to absorb water vapor from the surrounding atmosphere. According to the data in Figure 4, different homogenization methods can have an effect on the moisture content.

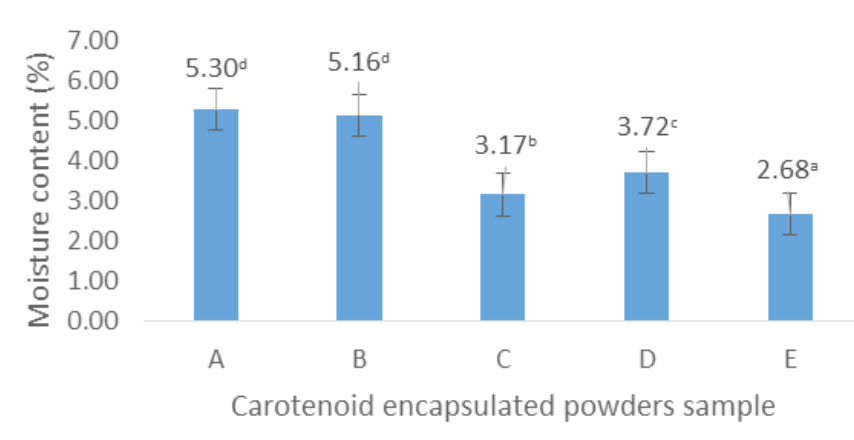

Figure 3. The moisture content of A. platensis carotenoid encapsulated with Arabic Gum and Whey Protein Concentrate. Description: Different superscripts shows that there are significant differences $(\mathrm{p}<0.05)$ : A : High Speed Homogenizer (HSH) 24,000 rpm, $90 \mathrm{~s}$; B : HSH 24,000 rpm, $60 \mathrm{~s}$, Ultrasound (US) Amplitude $55 \%, 120$ s; C : US Amplitude $94 \%, 138$ s; D : US Amplitude $55 \%, 138$ s; E US Amplitude $55 \%, 120$ s

\subsection{Antioxidant Activity}

The radical scavenging activity of the $A$. platensis carotenoid capsule from five different emulsification processes was in the range of 37.14 - $66.26 \%$ (Figure 4). Based on statistical analysis by ANOVA, the data showed that sample D (55\% amplitude level for 138 seconds) had the highest antioxidant activity and sample E (55\% amplitude level for 120 seconds) was in second place, but there was no significant difference with sample B $(p>0.05)$.

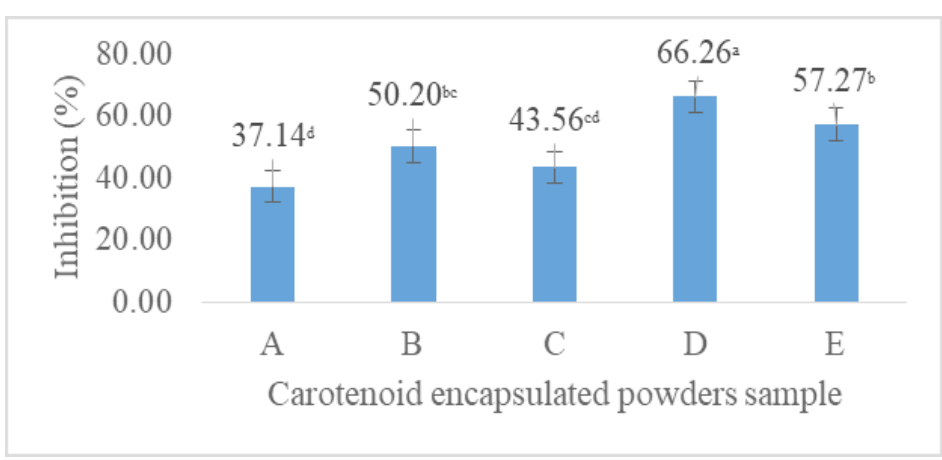

Figure 4. Antioxidant activity of A. platensis carotenoid nanocapules encapsulated with Arabic Gum and Whey Protein Concentrate. Description: Different superscripts shows that there are significant differences $(\mathrm{p}<0.05)$ : A : High Speed Homogenizer (HSH) 24,000 rpm, 90 s; B : HSH 24,000 rpm, $60 \mathrm{~s}$, Ultrasound (US) Amplitude $55 \%, 120$ s; C : US Amplitude $94 \%, 138$ s; D : US

Samples D and E undergo homogenization by the US with an amplitude of 55\% for 138 seconds and 55\% 
for 120 seconds, respectively. Compared with sample B, which undergo homogenization by HSH 24,000 rpm for 60 seconds and the US with an amplitude of $94 \%$ for 138 seconds, there was no significant different with sample $\mathrm{E}(\mathrm{p}>0.05)$. The scavenging activity did not rise linearly with increasing amplitude of US applied to the emulsion phase, indicating that the energy input mechanism was not the only factor affecting the carotenoid capsules' total antioxidant activity. Tan and Nakajima (2005) and Yi et al. (2014) hypothesize that emulsions with smaller particle sizes may promote the oxidation of the oil phase and decrease the bioactivity of the oil droplets. McClements and Decker (2000) mentioned that lipid oxidation can be accelerated by reactions that take place at the surface of the emulsion droplets. The carotenoids lost in the microcapsules can be directly attributed to oxygen exposure during encapsulation formation by the homogenization speed, which may have caused the oxidation. The crucial factor of the microencapsulation production is the controlled release, which ensures the release of carotenoid compounds in the human body after consumption (Lima et al., 2019).

\section{Conclusion}

The current study confirmed that the homogenization process depends on material from both the core and wall material to produce an emulsion and capsules with good stability and small particle size. The particle size was influenced by the emulsification process, such as homogenization treatment, homogenization time, amplitude, and time of sonication. The sample that was homogenized using both high-speed homogenizer and ultrasound had a smallest particle size and best encapsulation effectiveness. In general, combining the process homogenization can improve particle size reduction efficacy.

\section{Acknowledgment}

Thank you to the Department of Fisheries Faculty of Agriculture Universitas Gadjah Mada for supporting and facilitating this research.

\section{Authors' Contribution}

All authors have contributed to the final manuscript. The contributions of each author are as follows, Khusnul Alfionita; carried out the experiment, collected data, and wrote the manuscript. Siti Ari Budhiyanti; designed the research and wrote the manuscript. Nurfitri Ekantari; designed the research, analyzed the data and wrote the manuscript. All authors read and approved the final manuscript.

\section{Conflict of Interest}

The authors stated and declared that there is no conflict of interest in this research.

\section{Funding Information}

This research was funded by Featured Research Grants Faculty of Agriculture Universitas Gadjah Mada with Grant Number 1688/PN/PT/2019.

\section{References}

Alcântara, M. A., de Lima, A. E. A., Braga, A. L. M., Tonon, R. V., Galdeno, M. C., Mattos, M. D. C., Brígida, A. I. S., Rosenhaim, R., dos Santos, N. A., \& Cordeiro, A. M. T. M. (2019). Influence of the emulsion homogenization method on the stability of chia oil microencapsulated by spray drying. Powder Technology, 354:877-885.

Alfionita, K, Budhiyanti, S. A., \& Husni. A. (2017). Pengaruh pengemas dan suhu terhadap stabilitas karotenoid nanokapsul Spirulina platensis dengan enkapsulan gum arab dan WPC selama penyimpanan. Yogyakarta: Universitas Gadjah Mada.

Bajac, J. D., Nikolovski, B. G., Nesterović, A. G., Lončarević, I. S., \& Petrović, J. S. (2019). Determination of optimal ultrasound conditions for preparation of $\mathrm{O} / \mathrm{W}$ emulsions with encapsulated juniper berry essential oil (Juniperus communis L.). Acta Perodica Technologica, 2019(50):23-32.

Behbahani, E. S., Ghaedi, M., Abbaspour, M., \& Rostamizadeh, K. (2017). Optimization and characterization of ultrasound assisted preparation of curcumin-loaded solid lipid nanoparticles: Application of central composite design, thermal analysis and X-ray diffraction techniques. Ultrasonics Sonochemistry, 28:271280 .

Belay. A. (2007). Spirulina (Arthrospira): Production and quality assurance ( $1^{\text {st }}$ ed.). In Spirulina in Human Nutrition and Health. USA: CRC Press.

Carneiro, H. C.F., Tonon, R.V., Grosso, C. R. F., 
\& Hubinger, M. D. (2013). Encapsulation efficiency and oxidative stability of flaxseed oil microencapsulated by spray drying using different wall materials. Journal of Food Engineering, 115(4):443-451.

Chen, H., \& Zhong, Q. (2015). A Novel method of preparing stable zein nanoparticle dispersions for encapsulation of peppermint oil. Food Hydrocolloids, 43:593-602.

Chemat, F., Zill-e-Huma, \& Khan, M. K. (2011). Application of ultrasound in food technology: Processing, preservation, and extraction. Ultrasonics Sonochemistry, 18(4):813-835.

Cho, Y. H., Kim, S., Bae, E. K., Mok, C. K., \& Park, J. (2008). Formulation of a cosurfactant-free $\mathrm{O} / \mathrm{W}$ microemulsion using nonionic surfactant mixtures. Food Engineering and Physical Properties, 73(3):115-121.

Crouter, A., \& Briens, L. (2014). The effect of moisture on the flowability of pharmaceutical excipients. American Association of Pharmaceutical Scientists, 15(1):65-74.

Desorby, S. A., Netto, F. M., \& Labuza, T. P. (1997). Comparison of spray drying, drum drying, and freeze drying for $\beta$-carotene encapsulation and preservation. Journal of Food Science, 62(6):1158-1162.

Dias, M. I., Ferreira, I. C. F. R., \& Barreiro, M. F. (2015). Microencapsulation of bioactives for food applications. Food and Function, 6(4):10351052.

Fang, X., Shima, M., \& Adachi, S. (2005). Effects of drying conditions on the oxidation of linoleic Acid encapsulated with gum arabic by spray drying. Food Science and Technology Research, 11(4):380-384.

Ferreira, C. D., \& Nunes, I. L. (2019). Oil nanoencapsulation: Development, application, and incorporation into the food market. Nanoscale Research Letters, 14(9):1-13.

Gaikwad, S. G., \& Pandit, A. B. (2008). Ultrasound emulsification: Effect of ultrasonic and physicochemical properties on dispersed phase volume and droplet size. Ultrasonics Sonochemistry 15(4):554-563.
Gaumet, M., Vargas, A., Gurny, R., \& Delie, F. (2008). Nanoparticles for drug delivery: The need for precision in reporting particle size parameters. European Journal of Pharmaceutical and Biopharmaceutics, 69(1):1-9.

Ghosh, S., \& Rousseau, D. (2011). Fat crystals and water-in-oil emulsion stability. Current Opinion in Colloid \& Interface Science, 16(5):421-431.

Given, P. S. (2009). Encapsulation of flavors in emulsions for beverages. Current Opinion in Colloid \& Interface Science, 14(1):43-47.

Hakansson A. \& Rayner, M. (2018). Nanoemulsions: Formulation, applications, characterization. In General principles of nanoemulsion formation by high-energy mechanical methods. Netherland: Elsevier Science

Hashtjin, A. M., \& Abbasi, S. (2015). Optimization of ultrasonic emulsification conditions for the production of orange peel essential oil nanoemulsions. Journal Food Science and Technology, 52(5):2679-2689.

Hidayat, R., Budhiyanti, S. A., \& Husni, A. (2016). Pengaruh suhu spray drying terhadap karakteristik nanokapsul karotenoid dari Spirulina platensis dengan enkapsulan gum arab dan konsentrat protein whey. Yogyakarta: Universitas Gadjah Mada.

Higuera-Barraza, O. A., Torres-Arreola, W., EzquerraBrauer, J. M. Cinco-Moroyoqui, F. J., Figueroa, J. C. R., \& Marquez-Ríos, E. (2017). Effect of pulsed ultrasound on the physicochemical characteristics and emulsifying properties of squid (Dosidicus gigas) mantle protein. Ultrasonics Sonochemistry 38:829-834.

Hussathirak, K., Suwakul, W., \& Charnvanich, D. (2019). The effect of process parameters on physical characteristics of nanostructured lipid carriers using ultrasonication method. Paper presented at the $35^{\text {th }}$ International Annual Meeting in Pharmaceutical Sciences \& CU-MPU International Collaborative Research Conference, Bangkok, Thailand.

Jafari, S. M., He, Y., \& Bhandari, B. (2006). Nanoemulsion production by sonication and microfluidization-A comparison. International 
Journal of Food Properties, 9(3):475-485.

Kasperczyk, S., Dobrakowski, M., Kasperczyk, J., Ostalowska, A., Zalejska-Fiolka, J., \& Birkner, E. (2014). Beta-carotene reduces oxidative stress, improves glutathione metabolism and modifies antioxidant defense systems in leadexposed workers. Toxicology and Applied Pharmacology, 280(1):36-41.

Kerkhofs, S., Lipkens, H., Velghe, F., Verlooy, P., \& Martens, J. A. (2011). Mayonnaise production in batch and continuous process exploiting magnetohydrodynamic force. Journal of Food Engineering, 106(1):35-39.

Krishnan, S., Bhosale, R., \& Singhal, R. S. (2005). Microencapsulation of cardamom oleoresin: Evaluation of blends of gum arabic, maltodextrin and a modified starch as wall materials. Carbohydrate Polymers, 61(1):95-102.

Kumalasari, A. R., \& Budhiyanti, S. A. (2015). Pengaruh konsentrasi karotenoid dari Spirulina platensis terhadap karakteristik nanokapsul dengan enkapsulan konsentrat protein whey dan gum arab. Yogyakarta: Universitas Gadjah Mada.

Létang, C., Piau, M., Verdier, C., \& Lefebure, L. (2001). Characterization of wheat-flour-water doughs: A new method using ultrasound. Ultrasonics, 39(2):133-141.

Li, C., Li, X., Li, S., Weng, Y., Wang, K., Zhang, T., Chen, S., Lu, X., Jiang, Y., Xu, J., \& Liang, X. (2016). Development and validation of a method for determination of encapsulation efficiency of CPT-11/DSPE mPEG 2000 nanoparticles. Medicinal Chemistry, 6(5):345-348.

Li,P.H., \& Chiang, B.H.(2012). Processoptimization and stability of D-limonene-in-water nanoemulsions prepared by ultrasonic emulsification using response surface methodology. Ultrasonic Sonochemistry, 19(1):192-197.

Liang, R., Shoemaker, C. F., Yang, X., Zhong, F., \& Huang, Q. (2013). Stability and bioaccessibility of $\beta$-carotene in nanoemulsions stabilized by modified starches. Journal of Agricultural and Food Chemistry, 61(6):1249-1257.

Lima, F. F., Lescano, C. H., Oliveira, E. F. R., Fakhouri, F. M., Moraes, I. C. F., Kassuya, C. A. L., \&
Sanjinez-Argandona, E. J. (2019). Characterization and optimization of oil microcapsules from Attalea phalerata mart. For the preservation of bioactive compounds. Brazilian Journal of Pharmaceutical Sciences, 55:1-9.

Maher, P. G., Roos, Y. H., \& Fenelon, M. A. (2014). Physicochemical properties of spray dried nanoemulsions with varying final water and sugar contents. Journal of Food Engineering, 126:113-119.

Mani, V., Iyer, M., Dhruy, A., Mani, U., \& Sharma S. (2008). Therapeutic Utility Spirulina. In M. E. Gershwin and A. Belay (Ed.), Spirulina human nutrition and health. (pp. 71-100). Boca Raton: CRC Press.

Mao, L., Yang, J., Xu, D., Yuan, F., \& Gao, Y. (2010). Effects of homogenization models and emulsifiers on the physicochemical properties of $\beta$-carotene nanoemulsions. Journal of Dispersion Science and Technology, 31(7):986993.

Maphosa, Y., Jideani, V. A., \& Adeyi, O. (2017). Effect of soluble dietary fibres from bambara groundnut varieties on the stability of orange oil beverage emulsion. African Journal of Science, Technology, Innovation and Development, 9(1):69-76.

McClements, D. J., \& Decker, E. A. (2000). Lipid oxidation in oil-in-water emulsions: Impact of molecular environment on chemical reactions in heterogeneous food systems. Journal of Food Science, 65(8):1270-1282.

McClements, D. J., \& Rao, J. (2011). Food-grade nanoemulsions: Formulation, fabrication, properties, performance, biological fate, and potential toxicity. Critical Reviews in Foods and Nutrition, 51(4):285-330.

McClements, D. J. (2004). Protein-stabilized emulsions. Current Opinion in Colloid \& Interface Science, 9(5):305-313.

McClements, D. J. (2005). Food emulsions principles, practices and techniques ( $2^{\text {nd }}$ ed.). Boca Raton: CRC Press.

Meybodi, N. M., Mohammadifar, M. A., \& Naseri, A. R. (2014). Effective factors on the stability of oil- 
in-water emulsion based beverage: A review. Journal of Food Quality and Hazards Control, 1(3): 67-71.

Mohammed, N. K., Tan, C. P., Manap, Y. A., Muhialdin, B. J., \& Hussin, A. S. (2020). Spray drying for the encapsulation oils-A review. Molecules, 25(17):3873.

Mohanraj, V. J., \& Chen, Y. (2006). Nanoparticles-A review. Tropical Journal of Pharmaceutical Research, 5(1):561-573.

Mosquera, L. H., Moraga, G., \& Martinez-Navarrete, N. (2012). Critical water activity and critical water content of freeze dried strawberry powder as affected by maltodextrin and arabic gum. Food Research International, 47(2):201-206.

O'sullivan, A. M. N. (2013). Cellular and in-vitro models to assess antioxidant activities of seaweed extracts and the potential use of the extracts as ingredients. National University of Ireland. Philosophy in Food and Nutritional Sciences. $\mathrm{PhD}$ Thesis. Ireland: University College Cork.

Pahlevi, Y. W., Estiasih, T., \& Saparianti, E. (2008). Mikroenkapsulasi ekstrak karotenoid dari spora kapang oncom merah (Neurospora sp.) dengan bahan penyalut berbasis protein menggunakan metode pengeringan semprot. Jurnal Teknologi Pertanian, 9(1):31-39.

Peshkovsky, A. S., \& Bystryak, S. (2014). Continuousflow production of a pharmaceutical nanoemulsion by high-amplitude ultrasound: Process scale-up. Chemical Engineering and Processing, 82:132-136.

Prata, A. S., Garcia, L., Tonon, R. V., \& Hubinger, M. D. (2013). Wall material selection for encapsulation by spray drying. Journal of Colloid Science and Biotechnology, 2(2):1-7.

Qian, C., Decker, E. A., Xiao, H., \& McClements, D. J. (2012). Physical and chemical stability of $\beta$-carotene-enriched nanoemulsions: Influence of $\mathrm{pH}$, ionic strength, temperature, and emulsifier type. Food Chemistry, 132(3):12211229.

Reineccius, G. A. (2004). Multiple-core encapsulation: the spray drying of food ingredients. In Vilstrup, P. (Ed.), Microencapsulation of food ingredients. (pp. 151-
185). United Kingdom: Leatherhead International Limited.

Ricaurte, L., Perea-Flores, M. J., Martinez, A., \& Quintanilla-Carvajal, M. X. (2016). Production on high-oleic palm oil nanoemulsions by highshear homogenization (microfluidization). Innovative Food Science Emerging Technologies, 35:75-85.

Rodríguez, J., Martín, M. J., Ruiz, M. A., \& Clares, B. (2016). Current encapsulation strategies for bioactive oils: From alimentary to pharmaceutical perspectives. Food Research International, 83:41-59.

Rosanita, E. N. (2014). Mikroenkapsulasi $\beta$-karotenoid $S$. platensis dengan enkapsulan maltodekstrin dan konsentrat protein whey. Thesis. Yogyakarta: Universitas Gajah Mada.

Salvia,T.L., Qian,C.,Martin-Belloso, O.,\&McClements, D. J. (2013a). Influence of particle size on lipid digestion and $\beta$-carotene bioaccessibility in emulsions and nanoemulsions. Food Chemistry, 141(2):1472-1480.

Salvia, T. L., Qian, C., Martin-Belloso, O., \& McClements, D. J. (2013b). Modulating $\beta$-carotene bioaccessibility by controlling oil composition and concentration in edible nanoemulsions. Food Chemistry, 139(1-4):878884.

Sanguansri, P., \& Augustin, M. A. (2006). Nanoscale materials development-A food industry perspective. Trends Food Science Technology, 17(10):547-556.

Sherman, P. (1995). A critique of some methods proposed for evaluating the emulsifying capacity and emulsion stabilizing performance of vegetable proteins. Italian Journal of Food Science, 12(1):3-10.

Soottitantawat, A., Bigeardb, F., Yoshiia, H., Furutaa, T., Ohkawarac, M., \& Linkod, P. (2005). Microencapsulation of 1-menthol by spray drying and its release characteristics. Innovative Food Science \& Emerging Technologies, 6(2):163-170.

Sotiroudis, T. G., \& Sotiroudis, G. T. (2013). Health aspects of Spirulina (Arthrospira) microalga 
food supplement. Journal of the Serbian Chemical Society, 78(3):395-405.

Tadros, T. F. (2004). Application of rheology for assessment and prediction of the long-term physical stability of emulsions. Advances in Colloid and Interface Science, 108-109:227258.

Tadros, T. F. (2013). Emulsion formation, stability, and rheology ( $3^{\text {rd }}$ ed.). Germany: Wiley-VCH Verlag GmbH \& Compony KGaA.

Tan, C. P., \& Nakajima, M. (2005). $\beta$-carotene nanodispersions: Preparation, characterization and stability evaluation. Food Chemistry, 92(4):661-671.

Tanaka, T., Shnimizu, M., \& Moriwaki, H. (2012). Cancer chemoprevention by carotenoids. Molecules, 17(3):3202-3242.

Tomar, M., Kumar, S. A., \& Raj, S. A. (2017). Effect of moisture content of excipient (microcrystalline cellulose) on direct compressible solid dosage forms. International Journal of Pharmaceutical Sciences and Research, 8(1):282-288.

Tontul, I., \& Topuz, A. (2013). Mixture design approach in wall material selection and evaluation of ultrasonic emulsification in flaxseed oil microencapsulation. Drying Technology, 31(12):1362-1373.
Tontul, I., \& Topuz, A. (2015). Microencapsulation of plant oil rich in alpha-linolenic acid: Effect of processing parameters. Microencapsulation and Microspheres for Food Applications, 253269.

Vahidmoghadam, F., Pourahmad, R., Mortazavi, A., Davoodi, D., \& Azizinezhad, R. (2019). Characteristics of freeze-driednanoencapsulated fish oil with whey protein concentrate and gum Arabic as wall materials. Food Science and Technology, 1-7.

Vaidya, S., Bhosale, R., \& Singhal, R. S. (2006). Microencapsulation of cinnamon oleoresin by spray drying using different wall materials. Drying Technology, 24(8):983-992.

Wahyu, A. P., \& Yanuar, E. K. (2010). Optimasi proses ekstraksi pigmen karotenoid dari Spirulina plantesis. Semarang: Universitas Diponegoro.

Yi, J., Li, Y., Zhong, F., \& Yokoyama, W. (2014). The physicochemical stability and in vitro bioaccesibility of beta-carotene in oil-inwater sodium caseinate emulsions. Food Hydrocolloids, 35:19-27.

Yuan, Y., Gao, Y., Mao, L., \& Zhao, J. (2008). Optimisation of conditions for the preparation of [Beta]-carotene nanoemulsions using response surface methodology. Food Chemistry, 107(3):300-1306. 